\title{
Article
}

\section{Efficiency of disengaged wet brake packs}

Leighton, M, Morris, Nicholas, Trimmer, Gareth, King, Paul D. and Rahnejat, Homer

Available at http://clok.uclan.ac.uk/32115/

Leighton, M, Morris, Nicholas, Trimmer, Gareth, King, Paul D. and Rahnejat, Homer ORCID: 0000-0003-2257-7102 (2019) Efficiency of disengaged wet brake packs. Proceedings of the Institution of Mechanical Engineers, Part D: Journal of Automobile Engineering, 233 (6). pp. 1562-1569. ISSN 0954-4070

It is advisable to refer to the publisher's version if you intend to cite from the work. http://dx.doi.org/10.1177/0954407018758567

For more information about UCLan's research in this area go to http://www.uclan.ac.uk/researchgroups/ and search for <name of research Group>.

For information about Research generally at UCLan please go to http://www.uclan.ac.uk/research/

All outputs in CLoK are protected by Intellectual Property Rights law, including Copyright law. Copyright, IPR and Moral Rights for the works on this site are retained by the individual authors and/or other copyright owners. Terms and conditions for use of this material are defined in the policies page.

\section{CLoK}

Central Lancashire online Knowledge www.clok.uclan.ac.uk

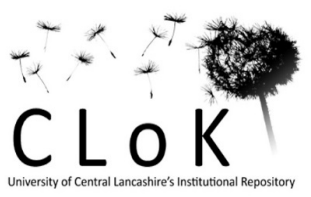


This item was submitted to Loughborough's Research Repository by the author.

Items in Figshare are protected by copyright, with all rights reserved, unless otherwise indicated.

\section{Efficiency of disengaged wet brake packs}

PLEASE CITE THE PUBLISHED VERSION

https://doi.org/10.1177/0954407018758567

PUBLISHER

(C) IMechE. Published by Sage

VERSION

AM (Accepted Manuscript)

PUBLISHER STATEMENT

This work is made available according to the conditions of the Creative Commons Attribution-NonCommercialNoDerivatives 4.0 International (CC BY-NC-ND 4.0) licence. Full details of this licence are available at: https://creativecommons.org/licenses/by-nc-nd/4.0/

\section{LICENCE}

CC BY-NC-ND 4.0

\section{REPOSITORY RECORD}

Leighton, Michael, Nick Morris, G. Trimmer, Paul King, and Homer Rahnejat. 2019. "Efficiency of Disengaged Wet Brake Packs". figshare. https://hdl.handle.net/2134/28406. 


\title{
Efficiency of Disengaged Wet Brake Packs
}

\author{
M. Leighton ${ }^{1}$, N. Morris ${ }^{1 *}$, G. Trimmer ${ }^{2}$, P.D. King ${ }^{1}$ and H. Rahnejat ${ }^{1}$ \\ ${ }^{1}$ Wolfson School of Mechanical, Electrical and Manufacturing Engineering, Loughborough University, \\ Leicestershire, LE11 3TU, UK, \\ ${ }^{2}$ J. C. Bamford Excavators, Rocester, Staffordshire, ST14 5JP, UK \\ *Corresponding author N.J.Morris@lboro.ac.uk
}

\begin{abstract}
Key objectives in off-highway vehicular powertrain development are fuel efficiency and environmental protection. As a result palliative measures are made to reduce parasitic frictional losses, whilst sustaining machine operational performance and reliability. A potential key contributor to the overall power loss is the rotation of disengaged wet multi-plate pack brake friction. Despite the numerous advantages of wet brake pack design, during high speed manoeuvre in highway travel or at start-up conditions significant frictional power losses occur. The addition of recessed grooves on the brake friction lining is used to dissipate heat during engagement. These complicate the prediction of performance of the system, particularly when disengaged. To characterise the losses produced by these components, a combined numerical and experimental approach is required. This paper presents a Reynolds-based numerical model including the effect of fluid inertia and squeeze film transience for prediction of performance of wet brake systems. Model predictions are compared with very detailed combined Navier-Stokes and Raleigh-Plesset fluid dynamics analysis to ascertain its degree of conformity to representative physical operating conditions, as well the use of a developed experimental rig. The combined numerical and experimental approach is used to predict significant losses produced during various operating conditions. It is shown that cavitation becomes significant at low temperatures due to micro-hydrodynamic action, enhanced by high fluid viscosity. The magnitude of the losses for these components under various operating conditions is presented. The combined numerical-experimental study of wet multi-plate brakes of off-highway vehicles with cavitation flow dynamics has not hitherto been reported in literature.
\end{abstract}


Keywords: Wet Brakes, Power loss, Efficiency, micro-hydrodynamics, Off-highway vehicles

\section{Nomenclature}

c Denotes the circumferential direction

$c_{r} \quad$ Denotes the cavitation reformation boundary

Err Error in the pressure convergence criterion

h Local plate separation/film thickness

I Inertial force

M Mass flow rate

n Number of spherical cavitation bubbles per unit volume

$N \quad$ Number of frictional surfaces

p Pressure

$p_{a} \quad$ Atmospheric pressure

$p_{v} \quad$ Vapour pressure

$r \quad$ Denotes the radial direction

$r_{b} \quad$ Bubble radius

$r_{i} \quad$ Inner radius of the annular friction plate

$r_{m} \quad$ Effective radius

$r_{o} \quad$ Outer radius of the annular friction plate

$R_{c} \quad$ Source term related to the collapse of vapour bubbles

$R_{e} \quad$ Source term related to the growth of vapour bubbles

$t \quad$ Time 
$\vec{V} \quad$ Velocity vector for the vapour phase

W $\quad$ Sliding speed in radial direction

Greek Letters

$\alpha \quad$ Vapour volume fraction

$\Delta_{i j} \quad$ Kronecker delta

$\eta \quad$ Lubricant dynamic viscosity

$\rho \quad$ Lubricant density

$\sigma \quad$ Cavitation number

$\omega \quad$ Angular velocity

$\tau \quad$ Viscous shear stress

\section{Introduction}

There is widespread use of off-highway vehicles in agriculture, construction and mining industries. Traditionally, these industries have prized these vehicles for their performance and reliability. In recent years the increasing cost of fuel has necessitated further optimisation of their powertrain system. Therefore, reduction of frictional power losses is a key objective in offhighway powertrain development. This also results in reduction of environmentally harmful emissions. One of the components targeted for improvement is the wet brake system whose design should also be affine to low wear, improved braking capacity and driveability [1].

The early design and development of wet disk brakes is focused mostly upon its reliability, braking capacity and driver experience [1-3]. Various wet brake designs were investigated for wear, Noise Vibration and Harshness $(\mathrm{NVH})$ and frictional performance during engagement using system level test rigs and full vehicle testing [1]. Anleitner [2] used an experimental approach to investigate the failure mode of the interfacial friction lining material as a function of brake engagement. A transient thermomechanical model was created by Zagrodzki [3] in order to 
investigate the influence of thermal deformations on the contact area and locally generated contact pressures during engagement. It was concluded that the friction lining materials with lower elastic moduli would reduce the unwanted thermo-mechanical phenomena.

Investigations of power loss produced by a disengaged wet brake and clutch packs have also been conducted [4-8]. A simple equation to predict drag torque in wet clutches under fully laminar flow was provided by Kitabayashi et al [4] as:

$T=\frac{N \eta \pi\left(r_{o}^{2}-r_{i}^{2}\right) \omega r_{m}^{2}}{h}$

However, this equation only takes into account contact separation of a pair of clutch plates, whereas the majority of clutch systems comprise multi-pair friction plates with complex groove patterns to aid heat transfer from their contacts. The same model was used for modelling simple wet clutch geometries and extended to consider the effect of cavitation [4]. A model, based upon Reynolds equation, including lubricant inertial flow was used by Pahlovy et al [5] to investigate the influence of various radial groove designs on the efficiency of wet clutch packs. Another study investigating wet clutch packs was presented by Razzaque and Kato [6], comprising a computational fluid dynamic model to include the effect of lubricant squeeze film effect during engagement. With separations between the clutch plates exceeding thin diminutive films, the fluid inertial effect becomes important. Furthermore, under transient conditions the squeeze film effect should also be taken into account. Inclusion of squeeze effect ensures the continuity of transient effect of changes upon plates' separations and can in fact enhance the load carrying capacity of the contact as has been shown in many load bearing applications, such as in bearings, gears, rings and seals [7-9].

In recent years a significant body of work has been reported for investigation of cavitation in wet clutch pack systems, commonly employed in motorbikes and automotive applications. A combined numerical-experimental analysis was conducted by Takagi et al [10] observing the cavitation phenomenon in wet clutch packs. Good conformance was obtained between the experimental results and a computational fluid dynamics model. A similar study was conducted by Pahlovy et al [11] who also measured the lubricant film pressures at the inner and the outer edges of the annular plates. 
The current study deviates for the cases reported in $[10,11]$ as the friction plate geometry is significantly larger in the case of off-highway vehicles and the lubricant for the clutch pack is commonly fed along the central shaft, whereas that for a brake disc lubricant is supplied through disc immersion into a sump of oil.

There have been various investigations of multi-disc-wet brake heat transfer, NVH and wear during engagement. There has also been some work on wet clutch losses during disengaged condition. However, a dearth of work exists regarding the extent to which the disengaged wet brake packs contribute to off-highway vehicle inefficiency. The braking torque requirement of these components creates significant differences in the component geometry when compared with wet clutch losses discussed in the literature. The influence of temperature on cavitation due to pressure perturbations caused by the cooling channel geometry and enhanced by high viscosity is also investigated. A combined numerical and experimental approach to contribute in this area of work is presented here. The drag losses and vapour volume fraction at various operating conditions are presented. The Navier-Stokes model considers the effect of lubricant churning and formation of foam. The findings and the approach expounded here has not hitherto been reported in literature.

\section{Disengaged Wet Brake Contact}

In a disengaged wet brake pack a difference in relative angular velocity can exist between the annular friction and the separator plates. In situ lubricant is supplied to the gap between the plates through their immersion into a sump and through centrifugal force due to their rotation. The supplied lubricant serves to dissipate the heat generated by contact friction during the instances of engagement of the brake plates. The lubricant also serves the differential gearing, housed within the same casing. Radial grooves pressed onto the friction lining allow lubricant flow even during full engagement (figure 1). The lubricant and the relative angular velocity of plate pairs, when disengaged, cause parasitic hydrodynamic losses. 


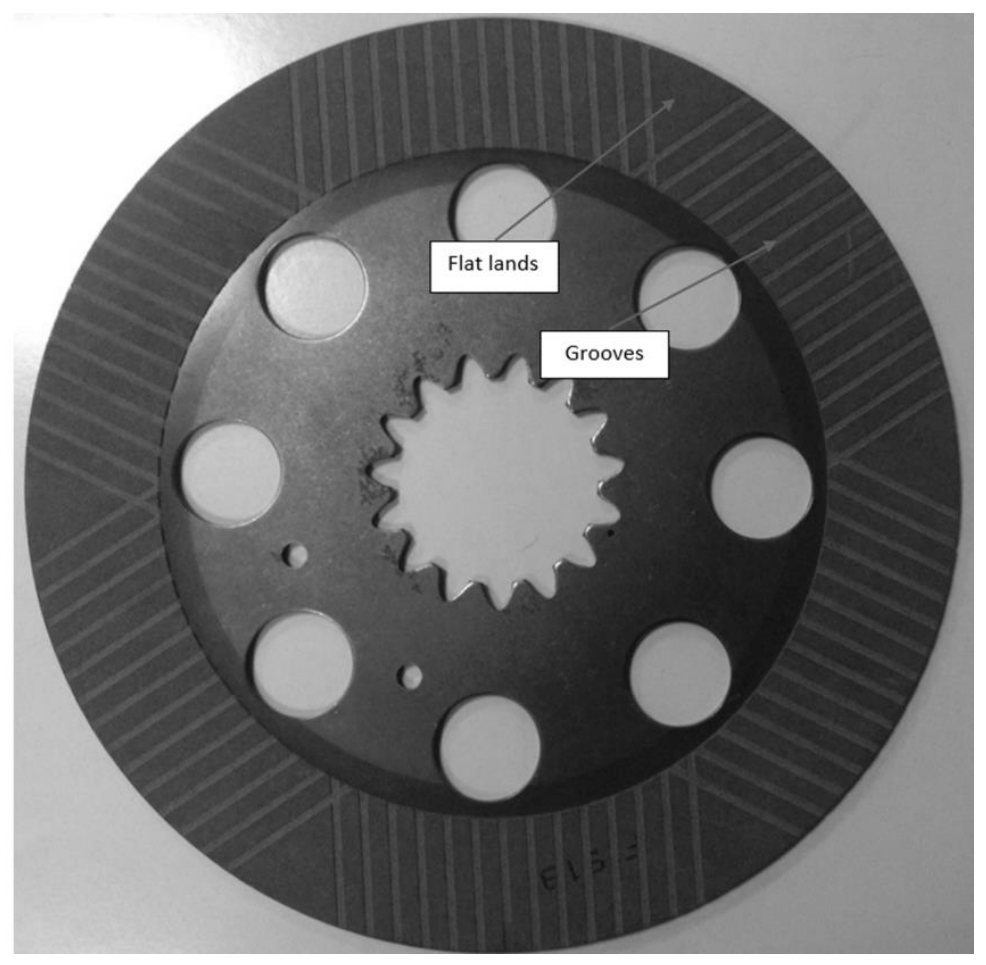

Figure 1: Friction plate design

A component-level test rig is developed in order to investigate the viscous frictional losses produced in contact of friction-separator plate pairs (figure 2). The test rig is driven by a motor, through a twin-pulley system, rotating a shaft upon which the friction plate resides. A torque transducer is connected in series between a torque limiting coupling and the friction plate. A flexible coupling connects the transducer to the input shaft in order to allow any minor misalignment. The driven shaft is rotated in a custom-built sump. Deep groove ball bearings support the shaft and are interference fitted to the sump housing structure with end caps and locking plates. The separator stator plates are separated relative to each other by fixed spacers at three clamped locations. The separator plate pairs are allowed to float axially and assume an equilibrium position with respect to the friction plate due to the generated hydrodynamic pressures. 


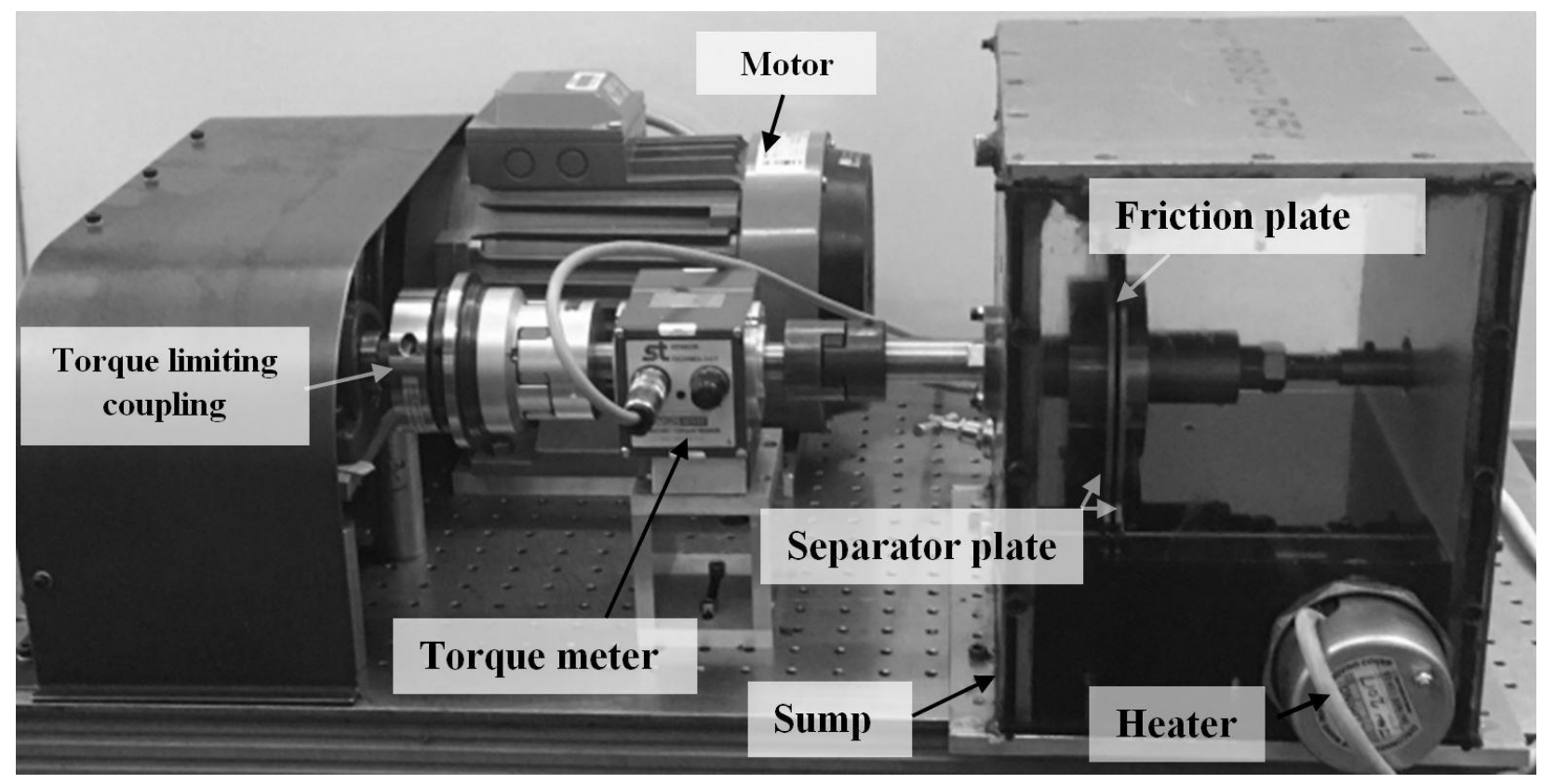

Figure 2. Component level test rig

To isolate the frictional torque generated at the friction-separator plate conjunction, the bearing and shaft losses are initially determined before the brake plates are assembled. The test rig is then assembled and run under dry sump conditions at $500 \mathrm{rpm}$ for 10 minutes in order to ensure that the bearings have reached thermal equilibrium. Measurements are then taken with a speed sweep in the range $0-1000 \mathrm{rpm}$ to obtain the generated resistive torque due to the ancillary components as a function of rotational speed.

The sump is then filled to the level of the bottom of the inner shaft radius, submerging the lower portion of the friction-separator plate contact. The lubricant in the sump is then heated to the desired operating temperature of interest, replicating the real world conditions of off-highway applications. The test rig is accelerated until the required operating speed is reached and then held constant at a constant speed in order to ensure consistent torque measurements. By subtracting the torque due the ancillary components from the total measured torque that attributed to the generated friction of separator plate conjunction can be determined. The simultaneous measurement of angular velocity allows the determination of power loss. 


\section{Numerical Model}

\section{Hydrodynamics}

The numerical model uses Reynolds equation with the inclusion of lubricant inertial flow and squeeze film effect to determine the frictional power loss of the disengaged friction plate:

$\frac{\partial}{\partial c}\left(h^{3} \frac{\partial p}{\partial c}\right)+\frac{\partial}{\partial r}\left(h^{3} \frac{\partial p}{\partial r}\right)-6 \eta\left(U_{1}+U_{2}\right) \frac{\partial h}{\partial c}-12 \eta \frac{\partial h}{\partial t}=-2 \rho h \frac{\partial h}{\partial c}\left(\frac{\partial I^{c c}}{\partial c}+\frac{\partial I^{c r}}{\partial r}\right)-2 \rho h \frac{\partial h}{\partial r}\left(\frac{\partial I^{c r}}{\partial c}+\right.$

$\left.\frac{\partial I^{r r}}{\partial r}\right)-\rho h^{2}\left(\frac{\partial^{2} I^{c c}}{\partial c^{2}}+2 \frac{\partial^{2} I^{c r}}{\partial c \partial r}+\frac{\partial^{2} I^{r r}}{\partial r^{2}}-\frac{\partial^{2} h}{\partial t^{2}}\right)-12 h\left(U_{1} \frac{\partial \eta}{\partial c}+W_{1} \frac{\partial \eta}{\partial r}\right)+2 h\left[\frac{\partial h}{\partial c}\left(\tau_{P h}^{c a}-\tau_{P 0}^{c a}\right)+\right.$

$\left.\frac{\partial h}{\partial r}\left(\tau_{P h}^{a r}-\tau_{P h}^{a r}\right)\right]+h^{2}\left[\frac{\partial}{\partial c}\left(\tau_{P h}^{c r}-\tau_{P 0}^{c r}\right)+\frac{\partial}{\partial r}\left(\tau_{P h}^{a r}-\tau_{P h}^{a r}\right)\right]$

where $\rho$ is the lubricant density, $I$ is its inertial and $\tau$ is the shear stress. $r$ denotes the radial direction, $c$ the circumferential direction, $h$ is the local separation of the plates, $p$ is pressure, $\eta$ is the lubricant dynamic viscosity and $U$ is the relative sliding speed.

A polar coordinate mesh density of $120 \times 960$ nodes in the radial and circumferential directions is used.

\section{Boundary conditions}

Since the geometry of the patterned sections of the brake plate have rotational symmetry every 60 degrees in circumferential direction, the computational time is reduced through application of periodic boundary conditions in the circumferential direction as:

$p(0, r)=p\left(\frac{\pi}{3}, r\right)$

The inner and outer radii of the meshed area are set to the atmospheric pressure which is a close approximation of the operating vehicle axle conditions.

$p\left(c, r_{i}\right)=p\left(c, r_{o}\right)=p_{a}$

Cavitation is taken into account through use of Swift-Stieber (Reynolds) lubricant film rupture and reformation boundary conditions. Principle of mass flow continuity is maintained in the cavitated region by estimating the lubricant volume fraction and assuming the residual nonlubricant volume to be gaseous flow at atmospheric pressure. Within the cavitated region, 
pressure-induced flow is assumed to diminish with a diminished pressure gradient at the reformation point, so that:

$\frac{d p}{d c}\left(c_{r}, r\right)=0$

\section{Solution procedure}

The developed numerical model applies a discretised Reynolds equation with the inclusion of lubricant inertia and squeeze film transience to the input measured brake geometry. Convergence of the iterative pressure loop is undertaken, such that the error between successive iterations is achieved through diminution by three orders of magnitude from any initial assumption, using Gauss-Seidel point successive over relaxation iterations. Areas of cavitation correspond to diminished pressure gradient with liquid lubricant film rupture. The lubricant transport in these regions is determined through principle of mass flow conservation. The convergence criterion is:

$E r r=\frac{\sum_{i=0}^{I} \sum_{j=0}^{J}\left|p_{i, j}^{n}-p_{i, j}^{o}\right|}{\sum_{i=0}^{I} \sum_{j=0}^{J} p_{i, j}^{n}}$

Where $p^{o}$ and $p^{n}$ are the pressures from a previous and the current iteration steps respectively.

\section{Friction and Power Loss}

The resistive frictional torque comprises pressure-induced Poiseuille flow, Couette flow as well as fluid inertial flow. Thus, the nodal friction is calculated as:

$F_{N}=\frac{\eta \cdot d c \cdot d r \cdot U}{h}+\frac{d p}{d c} \cdot h \cdot \frac{d c \cdot d r}{2}+\frac{d c \cdot d r \cdot h \cdot \rho \cdot M_{r} \cdot d M_{c}}{d r}$

For nodal areas within the cavitated regions, the wetted area is calculated through mass conservation, and the nodal friction becomes:

$F_{N}=\frac{\eta \cdot d c \cdot d r \cdot U \Pi_{c a v}}{h}+\frac{d c \cdot d r \cdot h \cdot \rho \cdot M_{r} \cdot d M_{c}}{d r}$

where $\Pi_{c a v}$ is the ratio of fluid volume to the total nodal volume.

Friction torque is then calculated as the sum of the nodal friction contributions multiplied by their radial positions. The resultant power loss becomes: 
$P_{L}=2 \pi T N_{r p s}$

\section{Navier-Stokes Model}

The Reynolds solution has the advantage of time-efficient computation, but it does not take into account the pressure into the depth of the lubricant film, which is important in the case of thicker films in disengaged plate pairs. Furthermore, cavitation may occur within the full film region of gaps of larger thickness as well as multi-layered flow characteristics of the lubricant through the contact as shown by Shahmohamadi et al $[12,13]$ in the case of diminutive films of piston compression ring-cylinder liner contact and those of big-end bearings of internal combustion engines, subjected to contact separation. Therefore, it is essential to carry out a flow analysis based on Navier-Stokes equations for two-phase flow through the contact. Such an analysis is computationally intensive with respect to the above expounded approach, but can be used as a method of ascertaining the extent of its validity.

\section{Governing equations}

Conservation of mass and momenta are obtained through use of Navier-Stokes equations, where the subscript $v$ denotes the vapour phase and $l$ the liquid phase [14]:

$\frac{D \rho_{l, v}}{D t}+\rho_{l, v} \nabla \cdot \vec{V}_{l, v}=0$

$\rho_{l, v} \frac{D \vec{V}_{l, v}}{D t}=-\nabla p_{l, v}+\nabla \cdot\left(\bar{\tau}_{i j}\right)$

The viscous shear stress tensor $\bar{\tau}_{i j}$ is:

$$
\bar{\tau}_{i j}=\eta\left(\frac{\partial u_{i}}{\partial x_{j}}+\frac{\partial u_{j}}{\partial x_{i}}-\frac{2}{3} \Delta_{i j} \nabla \cdot \vec{V}\right)
$$

where, $\eta$ is the lubricant dynamic viscosity, $\Delta_{i j}$ is the Kronecker delta and $\vec{V}$ the velocity vector: $u \hat{\imath}+v \hat{\jmath}+w \hat{k}$ in the three orthogonal Cartesian frame of reference: $(x, y, z)$.

\section{Cavitation model}

The converging-diverging geometry of the grooved features pressed onto the friction lining may promote cavitation within the contact. During testing it was observed that the lubricant in the 
sump is rapidly churned and aerated. In figure 3 the rotating disk can clearly be seen to cause the suspension of numerous micro-scale bubbles in the oil sump. To consider cavitation in a fluid containing a large number of spherical bubbles in suspension, Schnerr and Sauer [15] proposed a model which is used in the current analysis. The model assumes that the growth of vapour cavitation bubbles is initiated through heterogeneous nucleation.

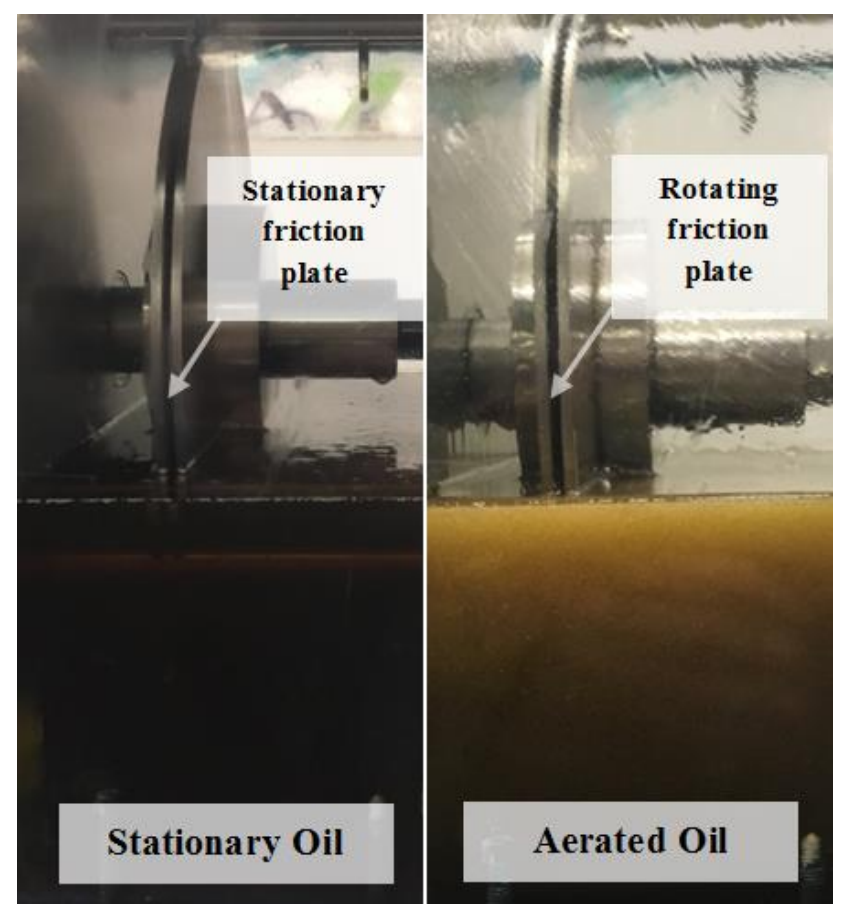

Figure 3: Image of sump with aerated oil

The liquid vapour mass transfer can be written as:

$R=R_{e}-R_{c}$

where $R_{e}$ and $R_{c}$ are the mass transfer due to bubble growth and collapse. This can be expressed as:

If: $p \leq p_{v}$, then: $R_{e}=\frac{P_{v} P_{l}}{\rho} \alpha(1-\alpha) \frac{3}{r_{b}} \sqrt{\frac{2}{3} \frac{\left(p_{v}-p\right)}{\rho_{l}}}$

Else, when: $p>p_{v}$, then: $R_{c}=\frac{P_{v} P_{l}}{\rho} \alpha(1-\alpha) \frac{3}{r_{b}} \sqrt{\frac{2}{3} \frac{\left(p-p_{v}\right)}{\rho_{l}}}$

The total mass transfer is governed by the vapour transport equation as: 
$R=\frac{\partial\left(\rho_{v} \alpha\right)}{\partial t}+\nabla\left(\rho_{v} \vec{V}_{v} \alpha\right)$

where $\alpha$ is the vapour volume fraction:

$\alpha=\frac{\frac{4}{3} \pi n r_{b}{ }^{3}}{1+\frac{4}{3} \pi r_{b}{ }^{3}}$

where the number of spherical bubbles per unit volume and vapour pressure are assumed to be $n=10^{13}$ and $80 \mathrm{kPa}$ respectively. The bubble dynamics; growth and collapse is accounted for by the Rayleigh-Plesset equation. A no-slip boundary condition is assumed between the disparate phases.

\section{Boundary conditions}

To reduce the mesh size and thus the analysis time a periodic boundary condition at the repeating edges is imposed. At the internal edge of the contact an inlet pressure is applied and the outlet pressure occurs at the external contact radius. The grooved friction plate face has an angular velocity about the centre of rotation. The flat separator plate is a considered as a stationary wall. The boundary conditions are shown in Figure 4 and are in-line with similar studies by Razzaque and Razzaque and Kato [6] and Cho et al [16].

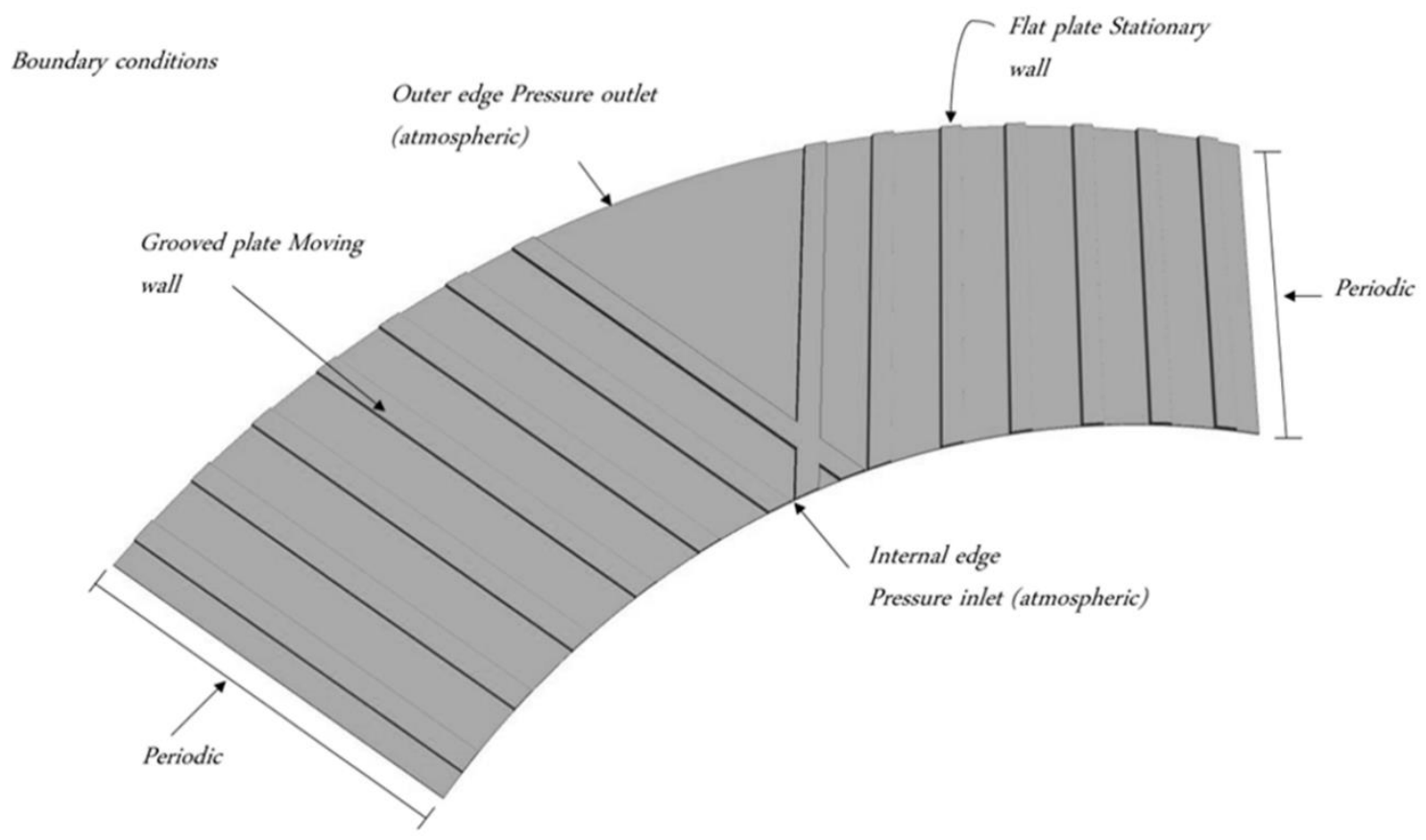

Figure 4: Boundary conditions for Navier-Stokes analysis 


\section{Meshing}

The geometry is spatially discretised using a mesh primarily comprising hexahedral elements. A tetrahedral mesh type is used at the complex groove intersections in the centre of the contact geometry. The mesh consists of $8 \times 10^{6}$ elements. The mesh at the periodic boundaries is required to be identically matched. A mesh dependency study is conducted using the conditions and parameters described in tables 1 and 2.

\section{Solution procedure}

A multi-phase mixture model [17] with a pressure-based solver using Semi-Implicit Method for Pressure-Linked Equations (SIMPLE) algorithm for velocity and pressure coupling is employed. For the spatial discretisation of momenta a second order upwind solver is used to minimise any discretisation errors.

\section{Results}

The bespoke friction-separator plate test rig is run under the conditions described in table 1 . The lower temperature is representative of a typical start-up condition $\left(20^{\circ} \mathrm{C}\right)$, the highest temperature is $70^{\circ} \mathrm{C}$, comparable to the axle casing bulk oil temperature. It should be noted that the temperature range specified is fairly conservative as the off-highway vehicles are often required to operate under extreme environmental conditions. A speed of $926 \mathrm{rpm}$ is chosen as it represents the relative rotational velocity between the friction and separator plates, typical of on-highway travel of these vehicles. The test rig measurements are simulated with the developed numerical models for comparative purposes. A typical transmission fluid is used, the rheological data for which is provided in table 2 .

Table 1: Conjunctional geometric data

\begin{tabular}{|l|l|}
\hline Inner Diameter & $160 \mathrm{~mm}$ \\
\hline Outer Diameter & $220 \mathrm{~mm}$ \\
\hline Rotation speed & $926 \mathrm{rpm}$ \\
\hline Minimum Separation & $200 \mu \mathrm{m}$ \\
\hline Temperature range & $20^{\circ} \mathrm{C}-70^{\circ} \mathrm{C}$ \\
\hline Groove depth & $500 \mu \mathrm{m}$ \\
\hline Groove pattern & Cross radial grooves (figure1) \\
\hline
\end{tabular}


Table 2: Lubricant rheological data

\begin{tabular}{|l|l|}
\hline Lubricant Dynamic Viscosity & $\begin{array}{l}7.7 \mathrm{cP}\left(\text { at } 100^{\circ} \mathrm{C}\right) \\
45.3 \mathrm{cP}\left(\text { at } 40^{\circ} \mathrm{C}\right)\end{array}$ \\
\hline Lubricant Density & $880 \mathrm{kgm}^{-3}\left(\right.$ at $\left.100^{\circ} \mathrm{C}\right)$ \\
\hline
\end{tabular}

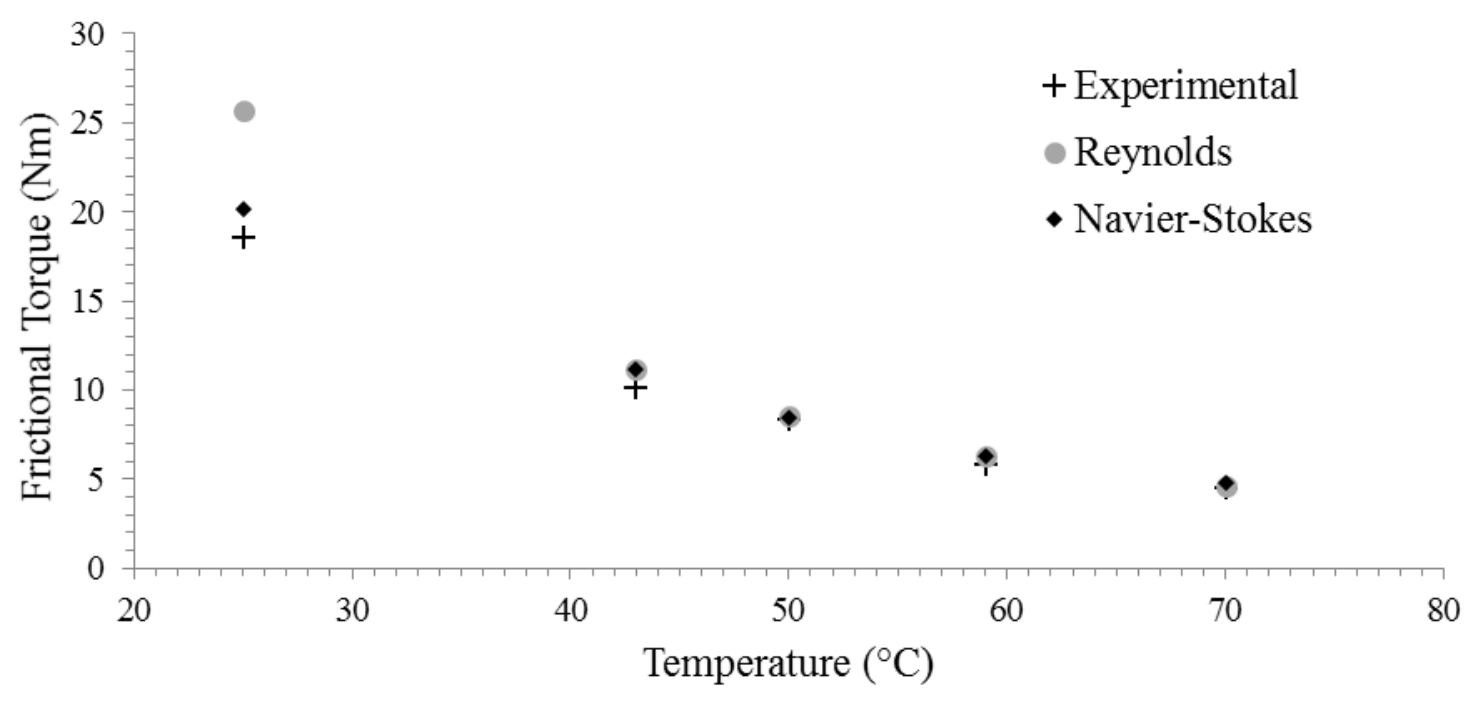

(a)

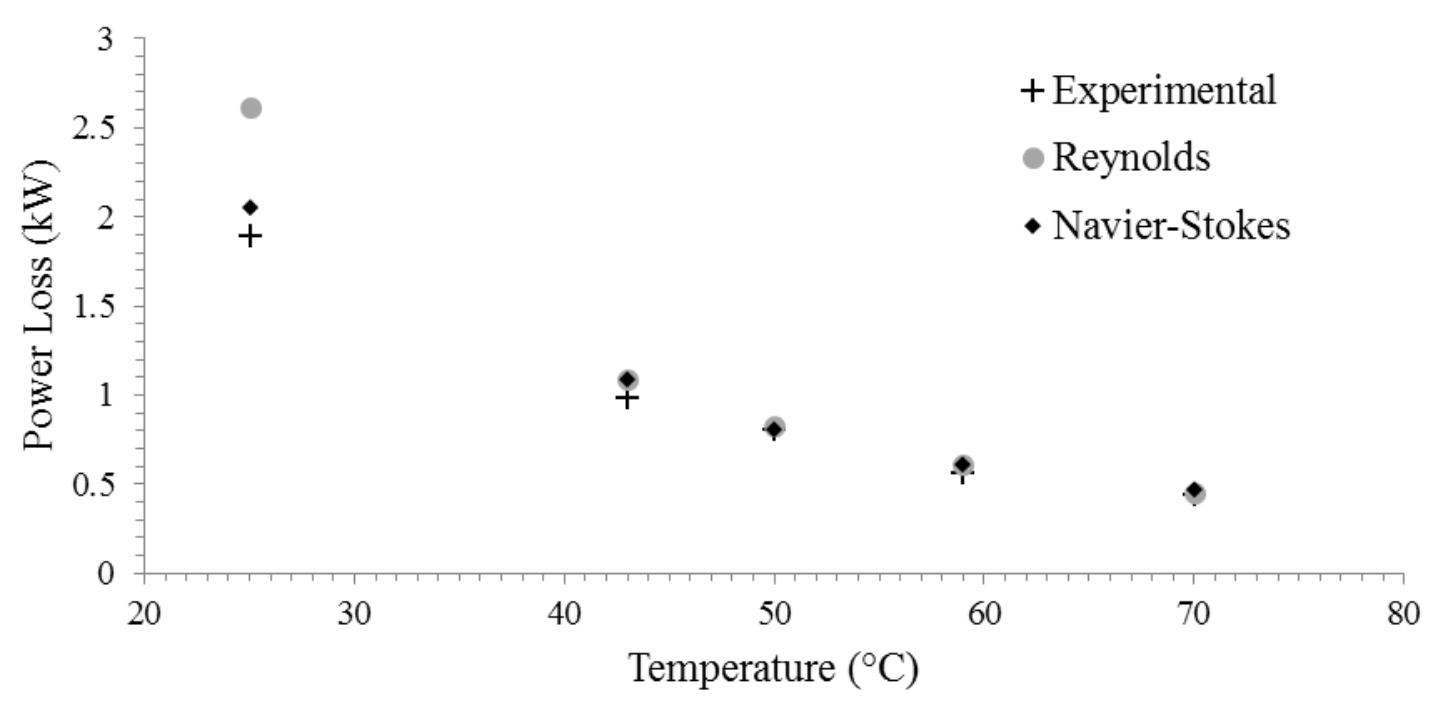

(b) 
Figure 5: Experimental measurements and numerical predictions for (a)- torque and (b)- and power loss of the brake pair at various operating temperatures

At higher temperatures with lower lubricant viscosity there is close agreement between the experimental and both methods of numerical analyses for frictional torque and Power loss (figures $5 \mathrm{a}$ and $5 \mathrm{~b}$ ). At the lower temperatures predictions of the Reynolds-based analysis diverges from the experimental measurements. However, the Navier-Stokes predictions are closer to the experimental measurements. At constant angular velocity and plates' separation the pressure fluctuations increase with higher lubricant viscosity. This is shown by the results of the Reynolds-based model at various temperatures (figure 6). Pressure perturbations occur at the edges of the grooves. This phenomenon is known as micro-hydrodynamics which leads to increased load carrying capacity of the contact. It is increasingly utilised in texturing of contacting surfaces as shown by Morris et al [18]. However, in the case of grooved brake friction discs the main purpose is to transfer the heat away from the contact by facilitating lubricant flow. It is thought that cavitation is induced by increased pressure perturbations, which is not sufficiently addressed by the Reynolds-based model.

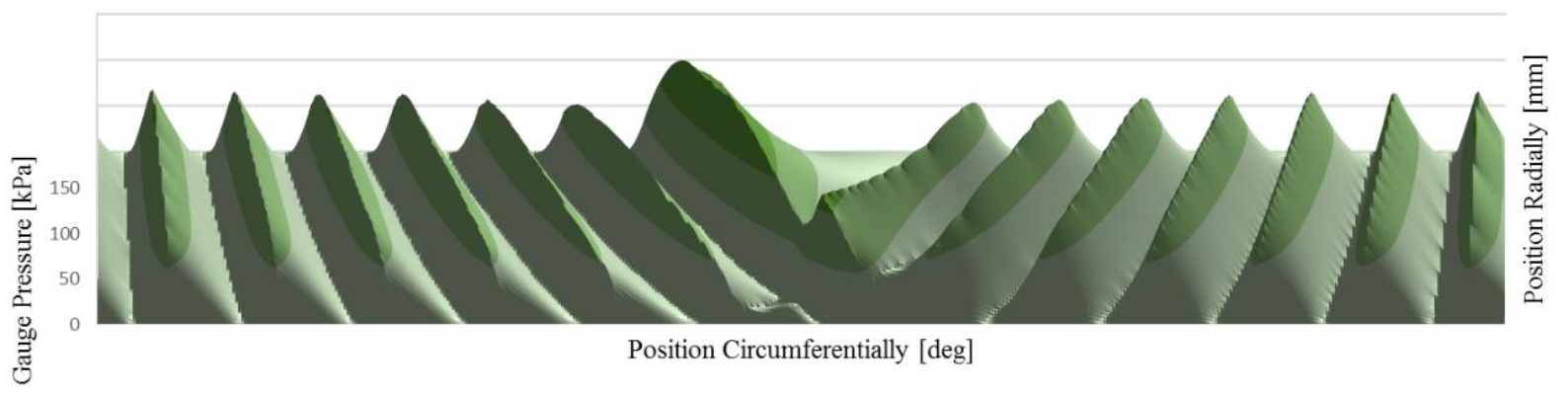

(a)

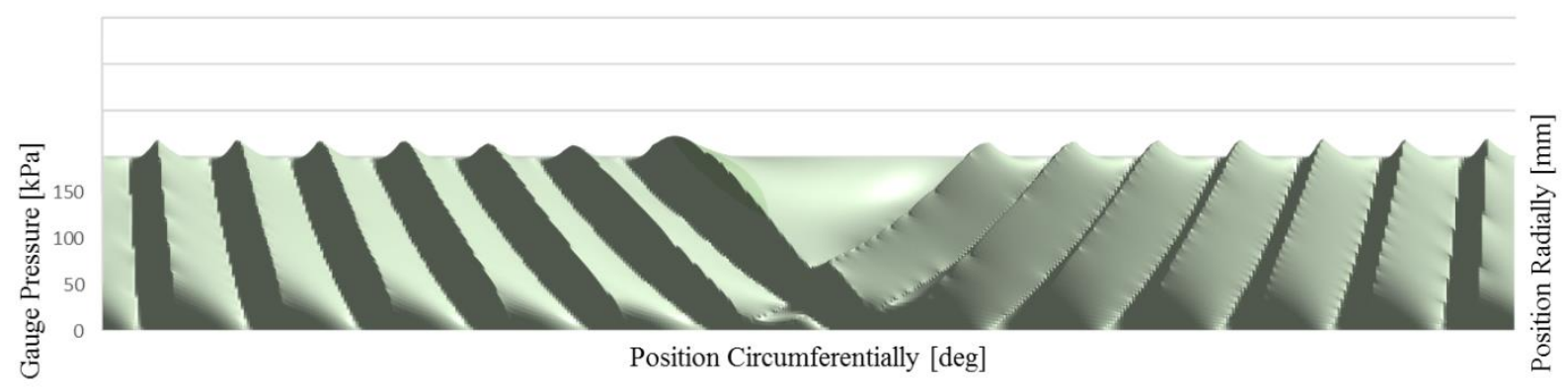


(b)

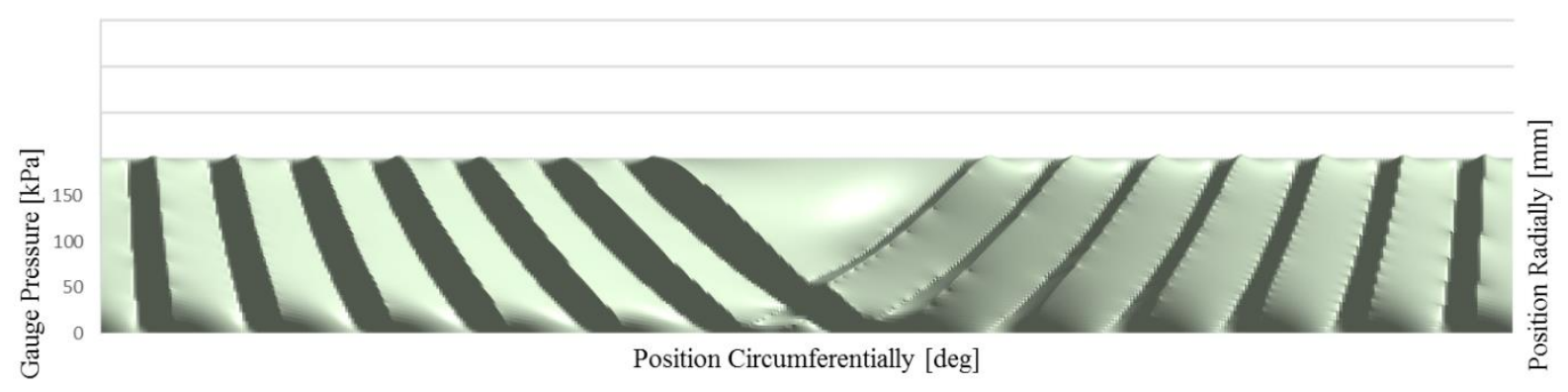

(c)

Figure 6: Pressure distributions calculated with the Reynolds-based model at various temperatures (a) $50^{\circ} \mathrm{C}$ (b) $75^{\circ} \mathrm{C}$ and (c) $100^{\circ} \mathrm{C}$

The results in figure 5 show that at lower lubricant viscosities the pressure perturbations, induced by groove geometry, are reduced and the Reynolds-based model is a suitable time efficient tool for analysis. For investigation of start-up conditions a full solution of Navier-Stokes with cavitation model is required to accurately represent the contact conjunction. The result can be explained with the use of the dimensionless cavitation number $(\sigma)$, where a smaller value of $\sigma$ indicates an increased propensity of the flow to cavitate:

$\sigma=\frac{p_{r}-p_{v}}{\frac{1}{2} \rho v^{2}}$

At lower temperatures, the lubricant viscosity increases and pressure perturbations are exacerbated. As a result the diverging regions of the flow experience lower generated pressures. The cavitation number shows that as fluid pressure decreases, there is an increased likelihood of the flow to cavitate.

The volume fraction predicted in the Navier-Stokes model is shown in figure 7. As expected the results indicate the influence of cavitation becomes significant at lower temperatures. The results help to explain the lower frictional torque observed in the experiment as the shear in the cavitated regions is significantly reduced compared with the fully wetted regions. 


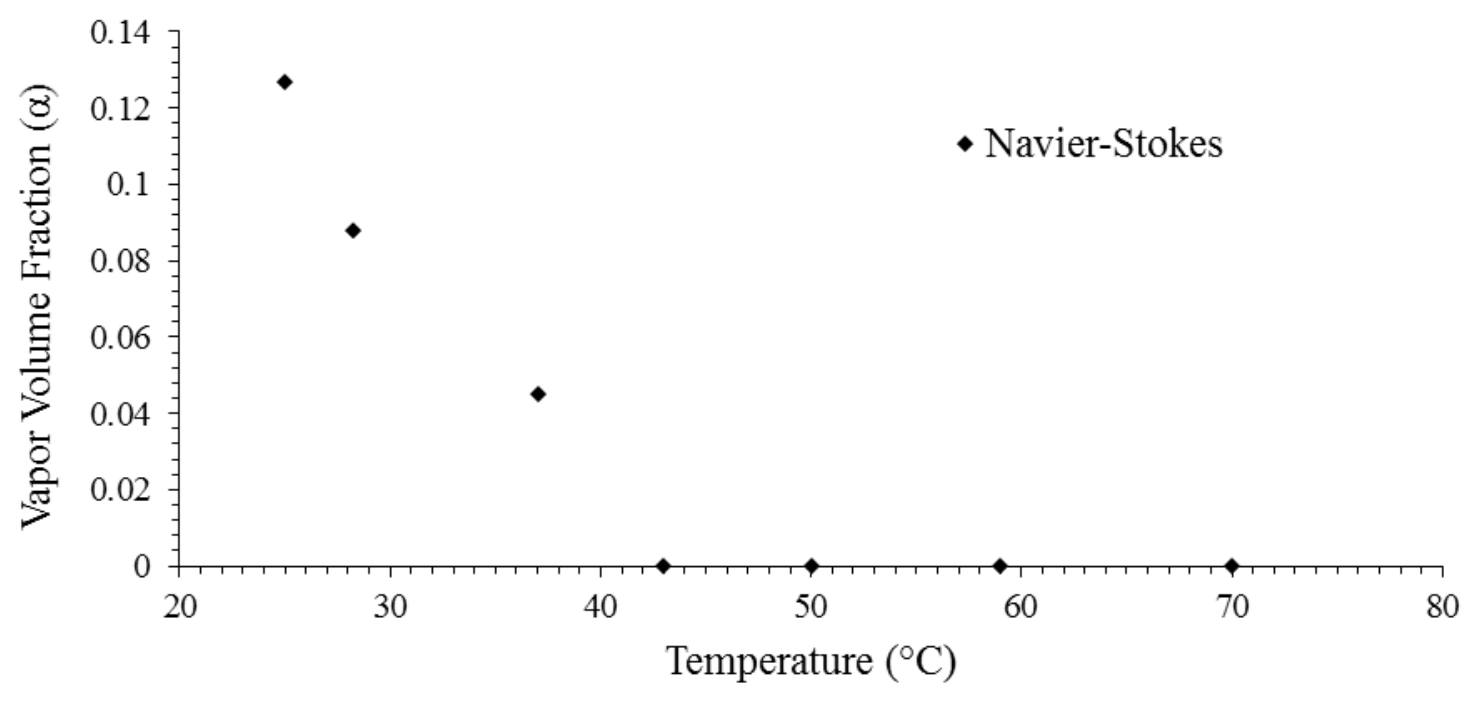

Figure 7: Predicted vapour volume fraction from Navier-Stokes under various thermal conditions

The frictional power loss for a dual 5 friction plate brake pack at high speed in highway travel is predicted by extrapolating the results from the experimental test rig and the Navier-Stokes model (figure 8). The frictional power loss during the start-up conditions is shown to be in the region of $20 \mathrm{~kW}$. Although this is a significant power loss, even higher losses would be expected during extreme low temperature climatic conditions under which off-highway vehicles are required to start up and operate. At thermal equilibrium, when a steady running temperature is achieved, the viscous drag is shown to be approximately $4.5 \mathrm{~kW}$. Whilst this is much lower than the start-up condition, it is nevertheless quite significant level and likely to be sustained for extended periods of on highway travel. 


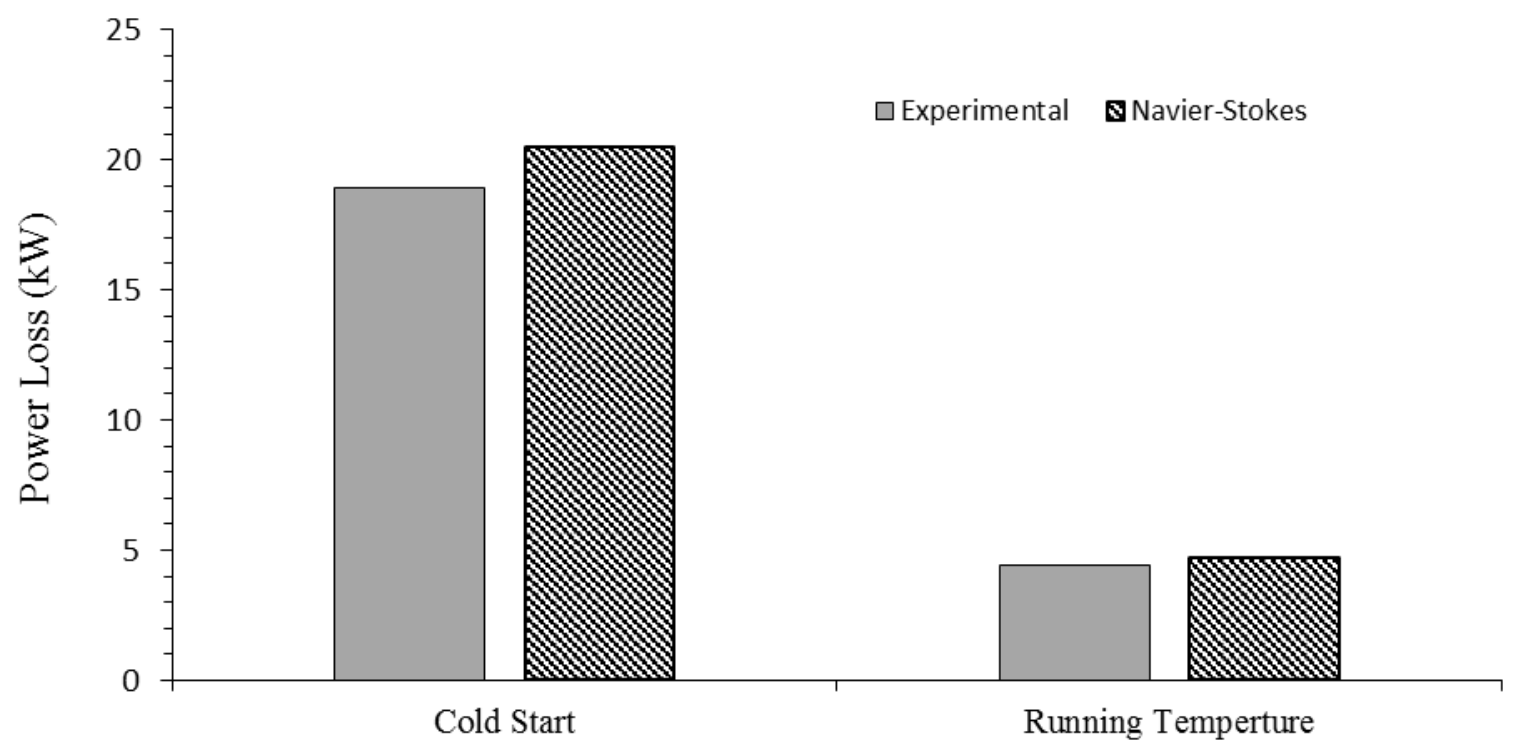

Figure 8: Predicted power loss for a 10 friction disk clutch pack cold start-up $\left(25^{\circ} \mathrm{C}\right)$ and running temperature $\left(75^{\circ} \mathrm{C}\right)$.

\section{Conclusions}

The disengaged wet brake system has been shown to produce significant viscous losses during various operating conditions. Under start-up conditions, it is predicted that the disengaged losses under high speed on highway operation would be in the region of $20 \mathrm{~kW}$. The significance of the braking losses for these components has not hitherto been reported in literature. These losses were identified using a combined numerical-experimental approach. The validated numerical models can now be applied to various brake friction lining patterns and operational parameters in order to optimise the design to minimise the power losses. The time-efficient Reynolds model is, however, only suitable for predictive analysis at lower lubricant viscosity, meaning higher operating conditions. In order to model the brake pack during start-up conditions a multi-phase mixture model, taking into account the effect of generated pressure perturbations and cavitation is required. Another key finding, not hitherto presented in literature, is the oil foam formation included in the Navier-Stokes model shows a significant effect on the onset of cavitation and drag loss at low temperatures. It is shown that this occurs as the result of increased pressure perturbations induced by the cooling channel geometry. Since, start up and other higher lubricant 
viscosity operating conditions represent only a small portion of the duty cycle, the developed Reynolds model represents an effective means for wet brake optimisation.

\section{Acknowledgements}

The authors would like to express their gratitude to J. C. Bamford Excavators and Innovate UK for their financial support of the reported research.

\section{References}

[1] Quick, D.C. and Sippel, L.F., "Design and development of wet disc brakes for agricultural tractors”, SAE Technical Paper, Pap. No. 730863,1973.

[2] Anleitner, M.A., "Friction Material Failure Modes in Oil-immersed Multiple Disk Brakes”, SAE Technical Paper, Pap. No. 841064, 1984.

[3] Zagrodzki, P., "Numerical analysis of temperature fields and thermal stresses in the friction discs of a multidisc wet clutch", Wear, 1985, 101(3), pp.255-271

[4] Kitabayashi, H., Li, C. and Hiraki, H., "Analysis of the Various Factors Affecting Drag Torque in Multiple-Plate Wet Clutches”, SAE Technical Paper, Pap. No. 2003-01-1973, 2003.

[5] Pahlovy, S., Mahmud, S., Kubota, M., Ogawa, M., and Takakura, N., "Multiphase Drag Modeling for Prediction of the Drag Torque Characteristics in Disengaged Wet Clutches", SAE Int., J. Commercial Vehicles, Pap. No. 2015-01-1977, 2014.

[6] Razzaque, M.M. and Kato, T., "Effects of groove orientation on hydrodynamic behaviour of wet clutch coolant films", Trans. ASME, J. Trib., 1999, 121(1), pp. 56-61

[7] Christensen, H., "Elastohydrodynamics of Normal Approach”, Proc. IMechE, 1967, 182 (1), pp. 248-261

[8] Rahnejat, H., "Influence of vibration on the oil film in concentrated contacts", $\mathrm{PhD}$ Thesis, Imperial College London, University of London, 1984. 
[9] Kushwaha, M. and Rahnejat, H., "Transient concentrated finite line roller-to-race contact under combined entraining, tilting and squeeze film motions", J. Physics, D: Applied Physics, 2004, 37(14):2018.

[10] Takagi, Y., "Effect of two-phase flow on drag torque in a wet clutch", J. Advanced Research in Physics, 2011, 2(2).

[11] Pahlovy, S.A., Mahmud, S.F., Kubota, M., Ogawa, M. and Takakura, N., "New Development of a Gas Cavitation Model for Evaluation of Drag Torque Characteristics in Disengaged Wet Clutches”, SAE Int., J. Engines, 2016, 9, 2016-01-1137, pp.1910-1915.

[12] Shahmohamadi, H., Rahmani, R., Rahnejat, H., Garner, C.P. and King, P.D., "Thermomixed hydrodynamics of piston compression ring conjunction”, Tribology Letters, 2013, 51(3), pp. 323-340.

[13] Shahmohamadi, H., Rahmani, R., Rahnejat, H., Garner, C.P. and Dowson, D., "Big end bearing losses with thermal cavitation flow under cylinder deactivation", Tribology Letters, 2015, 57(1):2.

[14] White, F.M., "Viscous Fluid Flow", 2nd edition, McGraw-Hill, New York, 1991.

[15] Schnerr, G.H. and Sauer, J., "Physical and numerical modeling of unsteady cavitation dynamics", $4^{\text {th }}$ Int. Conf. on Multiphase Flow, $27^{\text {th }}$ May $-1^{\text {st }}$ June 2001, New Orleans, USA.

[16] Cho, J., Katopodes, N., Kapas, N. and Fujii, Y., "CFD modelling of squeeze film flow in wet clutch”, SAE Technical Paper, No. 2011-01-1236, 2011.

[17] Manninen, M., Taivassalo, V. and Kallio, S., "On the mixture model for multiphase flow", VTT publications, 288, Technical Research Centre of Finland,1996.

[18] Morris, N., Leighton, M., De la Cruz, M., Rahmani, R., Rahnejat, H. and Howell-Smith, S., "Combined numerical and experimental investigation of the micro-hydrodynamics of chevronbased textured patterns influencing conjunctional friction of sliding contacts", Proc. IMechE, Part J: J. Engineering Tribology, 2015, 229(4), pp.316-335. 